\title{
The "GG" genotype of rs26802 variant in the ghrelin gene is a potential protective factor against nonalcoholic fatty liver disease
}

\author{
GHOLAMREZA REZAMAND ${ }^{1}$, TOURAJ MAHMOUDI ${ }^{2}$, \\ SEIDAMIR PASHA TABAEIAN ${ }^{1,3}$, HAMID FARAHANI $^{4 *}$, \\ FATEMEH SHAHINMEHR ${ }^{5}$, HOSSEIN NOBAKHT ${ }^{6}$, REZA DABIRI $^{6}$, \\ ASADOLLAH ASADI ${ }^{7}$, FARIBORZ MANSOUR-GHANAEI ${ }^{8}$ and \\ MOHAMMAD REZA ZALI ${ }^{2}$
}

\footnotetext{
${ }^{1}$ Colorectal Research Center, Iran University of Medical Sciences, Tehran, Iran

${ }^{2}$ Gastroenterology and Liver Diseases Research Center, Research Institute for Gastroenterology and Liver Diseases, Shahid Beheshti University of Medical Sciences, Tehran, Iran

${ }^{3}$ Department of Internal Medicine, School of Medicine, Iran University of Medical Sciences, Tehran, Iran

${ }^{4}$ Department of Physiology and Pharmacology, School of Medicine, Qom University of Medical Sciences, Qom, Iran

${ }^{5}$ Endocrine Research Center, Institute of Endocrinology and Metabolism, Iran University of Medical Sciences (IUMS), Tehran, Iran

${ }^{6}$ Internal Medicine Department, Semnan University of Medical Sciences, Semnan, Iran

${ }^{7}$ Department of Biology, Faculty of Science, University of Mohaghegh Ardabili, Ardabil, Iran

${ }^{8}$ Division of Gastroenterology and Hepatology, Gastrointestinal and Liver Diseases Research Center (GLDRC), Guilan University of Medical Sciences, Rasht, Iran
}

\footnotetext{
* Corresponding author. Department of Physiology and Pharmacology, School of Medicine, Qom University of Medical Sciences, Alqadir Boulevard, 3736175513, Qom, Iran. Tel.: +98 9126085708; fax: +98 2533209126. E-mail: farahani42@gmail.com
} 


\begin{abstract}
Background: Nonalcoholic fatty liver disease (NAFLD) is an emerging global chronic liver disease worldwide. Considering the powerful association between NAFLD, insulin resistance (IR) and obesity, as well as the key role of ghrelin in these metabolic disorders, we hypothesized that some single nucleotide polymorphisms (SNPs) of the ghrelin (GHRL) and ghrelin receptor (GHSR) genes might be associated with NAFLD. Methods: We conducted a case-control retrospective study of 150 cases with biopsyproven NAFLD and 155 controls. The diagnosis of NAFLD was established before the start of the genotyping process. All the 305 subjects were genotyped for GHRL SNP rs26802 or -501T >G and GHSR SNP rs572169 or Arg159Arg using the PCR-RFLP method. Results: The GHRL rs26802 "GG" genotype compared with the "TT" genotype and "TT+TG" genotype appears to be a marker of decreased NAFLD susceptibility even after adjustment for confounding factors $(\mathrm{P}=0.006$; $\mathrm{OR}=0.14,95 \% \mathrm{CI}=0.03$ 0.56 and $\mathrm{P}=0.003 ; \mathrm{OR}=0.16,95 \% \mathrm{CI}=0.05-0.53$, respectively). However, we observed no significant difference in genotype or allele frequencies between the cases and controls for GHSR SNP rs572169. Conclusions: These findings proposed, for the first time, that the GHRL rs26802 "GG" genotype has a protective effect against NAFLD. Nonetheless, this observation warrants further investigations in other populations.
\end{abstract}

\title{
KEYWORDS
}

ghrelin, GHRL, GHSR, NAFLD, obesity, SNP

\section{INTRODUCTION}

Nonalcoholic fatty liver disease (NAFLD) - the most common chronic liver disorder - is a serious and increasing public health concern, and its global prevalence is very high (25\%). NAFLD is considered to be the hepatic expression of the metabolic syndrome and is characterized by excessive hepatic fat content in the absence of excessive alcohol consumption. It encompasses a wide range of histological changes differing from simple steatosis to non-alcoholic steatohepatitis (NASH) with potential for progression to cirrhosis and hepatocellular carcinoma [1]. In spite of efforts, the etiology of NAFLD development and progression has not yet been fully comprehended. However, previous reports have suggested that the genes involved in insulin resistance (IR), obesity, and inflammation might be potential candidate genes for NAFLD. Patients with NAFLD are predisposed to obesity [2], IR [3], and type 2 diabetes (T2D) [4]. Furthermore, the increased levels of liver enzymes aspartate aminotransferase (AST) and alanine aminotransferase (ALT) - are much higher in NAFLD patients with IR compared with those without IR [5]. Moreover, patients with NASH compared with those with simple fatty liver have more severe IR [6]. A positive association has also been found between NAFLD and serum insulin levels [7]. Lastly, NAFLD has been associated with single nucleotide polymorphisms (SNPs) in insulin pathway-related genes [8-10].

There is growing evidence that ghrelin encoded by the GHRL gene and ghrelin receptor, also known as growth hormone $(\mathrm{GH})$ secretagogue receptor, encoded by the GHSR gene may play a role in the pathogenesis of NAFLD. Insulin secretion, IR, obesity, and NAFLD are all associated with alterations in circulating levels of ghrelin. Ghrelin is chiefly produced by the cells lining the 
fundus of the stomach with small amounts also released by the hypothalamus, pituitary, small intestine, pancreas, brain, lung, heart, and kidney. Ghrelin has a range of biological actions including regulation of energy homeostasis, modulation of insulin signaling, GH release through the activation of the GHSR, and anti-inflammatory effects [11,12]. Previous studies have also suggested negative associations between circulating ghrelin levels and body mass index (BMI) [13, 14], IR [13, 15], T2D [15], hypertension [15], and NAFLD [16]. The product of the other gene studied here, GHSR, mediates the effects of ghrelin; it is a G protein-coupled receptor and its gene is located on the long arm of chromosome 3 and encodes the GHSR protein.

Hence these observations led us to investigate whether GHRL and GHSR gene SNPs were associated with NAFLD.

\section{MATERIALS AND METHODS}

\section{Participants}

The study population consisted of 155 controls (age range, 32-82 years) and 150 cases with biopsy-proven NAFLD (age range, 31-87 years). All the 305 participants were Iranian and genetically unrelated, and they were informed about the aims of the study. Information on demographic, anthropometric, and clinical characteristics of the subjects was collected using a self-administered questionnaire. NAFLD was diagnosed based on the following criteria: (I) ultrasonographic evidence of fatty liver and high serum levels of liver enzymes (ALT, AST, gamma-glutamyl transferase or GGT); (II) alcohol consumption $<20 \mathrm{~g} \mathrm{day}^{-1}$ in men and $<10 \mathrm{~g} \mathrm{day}^{-1}$ in women; (III) excluding patients with other causes of liver disease including viral hepatitis, Wilson's disease, alpha-1 antitrypsin deficiency, and use of drugs known to induce steatosis; (IV) histologic confirmation of NAFLD by an experienced pathologist who was unaware of the patients' clinical and biochemical data and scored biopsies using the Brunt's criteria. Steatosis and necroinflammation were graded from 0 to 3 and fibrosis was staged from 0 to 4 [17]. The controls had neither liver steatosis (examined by abdominal ultrasonography), elevated liver enzymes, nor viral hepatitis infection (examined by a blood test). None of them was alcoholic or drank regularly either, and none was on regular medications. The control group was of the same geographical origin as the NAFLD patients and was selected from the institute staff and medical students. The study protocol was approved by the Ethical Review Boards of the Institution (No. 1426) and was conducted according to the principles of the Helsinki Declaration. BMI was calculated by the standard formula: weight $(\mathrm{kg}) /$ height squared $\left(\mathrm{m}^{2}\right)$.

\section{Genotype analysis}

In this case-control retrospective study, the diagnosis of NAFLD was established before the start of the genotyping. Genomic DNA was purified from $5 \mathrm{ml}$ EDTA-anti-coagulated whole blood using phenol-chloroform extraction and ethanol precipitation protocol. DNA quality and quantity were then determined by NanoDrop 1000 Spectrophotometer (Thermo Fisher Scientific Inc; Waltham, MA). The GHRL rs26802 and GHSR rs572169 SNPs were genotyped using 
PCR-RFLP method. The two SNPs were selected based on their relatively high minor allele frequency (MAF), use in the previous genetic studies, and functional importance. According to the dbSNP entry for the rs26802 SNP (https://www.ncbi.nlm.nih.gov/snp/rs26802), the MAF of rs26802 is $\mathrm{G}=0.31$ and for the rs572169 SNP (https://www.ncbi.nlm.nih.gov/snp/rs572169), the MAF of rs572169 is $\mathrm{T}=0.30$. Table 1 shows the details of the PCR and RFLP conditions [18]. The PCR products were digested by the appropriate restriction enzymes (Fermentas, LeonRot, Germany) and then the digested products were electrophoresed on 2.5-3.5\% agarose gels and stained with ethidium bromide $\left(0.5 \mu \mathrm{g} \mathrm{ml}^{-1}\right)$ for visualization on a UV light transilluminator. Genotyping of the subjects was denoted based on the digestion patterns and the presence or absence of the respective restriction enzyme sites (MwoI or TaqI). To check for genotyping error rate, we repeated the genotyping analysis of around $15 \%$ of the samples that were selected randomly.

\section{Statistical methods}

We used either chi-square $\left(\chi^{2}\right)$ test or $t$-test to compare the differences in demographic, anthropometric, or clinical parameters between the groups. Differences in the allele or genotype frequencies between the different groups were calculated using $\chi^{2}$ test or logistic regression analysis, respectively. Logistic regression was also applied to adjust confounding factors such as age and BMI. For all the alleles and genotypes, the odds ratios (OR) were given with the respective 95\% confidence intervals (95\% CI). For statistical analyses, we used SPSS software, version 25.0 (SPSS Inc. Chicago, IL, USA). $P$ values less than 0.05 were considered statistically significant.

\section{RESULTS}

Selected characteristics of the study population and their statistical significance are summarized in Table 2. NAFLD patients were older $(P<0.001)$ and more likely to be overweight/obese $(P<0.001)$, male $(P<0.001)$, and smoker $(P=0.007)$ than the controls. In addition, systolic blood pressure (SBP), diastolic blood pressure (DBP), and

Table 1. Information for the studied markers in ghrelin (GHRL) and ghrelin receptor (GHSR) genes

\begin{tabular}{lcccccc}
\hline $\begin{array}{l}\text { Gene } \\
(\text { SNP ID })\end{array}$ & $\begin{array}{c}\text { Location } \\
\text { (Base } \\
\text { change) }\end{array}$ & $\begin{array}{c}\text { Forward Primer } \\
\text { Reverse Primer }\end{array}$ & $\begin{array}{c}\text { PCR } \\
\text { Annealing } \\
\text { temperature }\end{array}$ & $\begin{array}{c}\text { PCR } \\
\text { fragment } \\
\text { size (bp) }\end{array}$ & $\begin{array}{c}\text { Restriction } \\
\text { enzyme }\end{array}$ & $\begin{array}{c}\text { RFLP } \\
\text { fragments } \\
\text { size (bp) }\end{array}$ \\
\hline $\begin{array}{c}\text { GHRL } \\
(\text { rs26802) }\end{array}$ & $\begin{array}{c}\text { Intron 1 } \\
(\mathrm{T} / \mathrm{G})\end{array}$ & $\begin{array}{c}5^{\prime} \text {-TTCCAGCCAGA } \\
\text { CAGTCCGAC-3 } \\
5^{\prime} \text {-AGAACAAACG }\end{array}$ & $61^{\circ} \mathrm{C}$ & 202 & MwoI & $\begin{array}{c}\text { T: } 202 \\
\text { CCAGTCATCC-3' }\end{array}$ \\
$\begin{array}{c}\text { GHSR } \\
(\mathrm{rs} 572169)\end{array}$ & $\begin{array}{c}\text { Exon 1 } \\
(\mathrm{C} / \mathrm{T})\end{array}$ & & $65^{\circ} \mathrm{C}$ & 263 & TaqI & C: 263 \\
\hline
\end{tabular}


Table 2. Characteristics of the nonalcoholic fatty liver disease (NAFLD) patients and the controls ${ }^{\mathrm{a}}$

\begin{tabular}{|c|c|c|c|}
\hline Variables & Controls $(n=155)$ & Patients $(n=150)$ & $P$-value \\
\hline Age (years) & $29.1(7.2)$ & $38.6(9.3)$ & $<0.001$ \\
\hline BMI $\left(\mathrm{kg} \mathrm{m}^{-2}\right)$ & $23.7(3.1)$ & $29.5(5.4)$ & $<0.001$ \\
\hline \multicolumn{4}{|l|}{ Sex } \\
\hline Male & $81(52.3)$ & $108(72.0)$ & \\
\hline Female & $74(47.7)$ & $42(28.0)$ & $<0.001$ \\
\hline \multicolumn{4}{|c|}{ Smoking history } \\
\hline No & $143(92.3)$ & $111(74.0)$ & \\
\hline Former & $9(5.8)$ & $18(12.0)$ & \\
\hline Current & $3(1.9)$ & $21(14.0)$ & 0.007 \\
\hline SBP (mmHg) & $114.5(13.1)$ & $123.9(15.4)$ & $<0.001$ \\
\hline DBP (mmHg) & $69.4(8.2)$ & $75.2(9.5)$ & $<0.001$ \\
\hline AST (IU/L) & $19.6(7.1)$ & $39.9(17.1)$ & $<0.001$ \\
\hline ALT (IU/L) & $19.7(10.5)$ & $71.2(40.8)$ & $<0.001$ \\
\hline GGT (IU/L) & $18.7(8.6)$ & $58.0(31.5)$ & $<0.001$ \\
\hline \multicolumn{4}{|l|}{ Steatosis } \\
\hline Grade 0 & & - & \\
\hline Grade 1 & & $39(26.0)$ & \\
\hline Grade 2 & & $80(53.3)$ & \\
\hline Grade 3 & & $31(20.7)$ & \\
\hline \multicolumn{4}{|c|}{ Necroinflammation } \\
\hline Grade 0 & & $45(30.0)$ & \\
\hline Grade 1 & & $58(38.7)$ & \\
\hline Grade 2 & & $45(30.0)$ & \\
\hline Grade 3 & & $2(1.3)$ & \\
\hline \multicolumn{4}{|l|}{ Fibrosis } \\
\hline Stage 0 & & $86(57.3)$ & \\
\hline Stage 1 & & $57(38.0)$ & \\
\hline Stage 2 & & $7(4.7)$ & \\
\hline Stage 3 & & - & \\
\hline Stage 4 & & - & \\
\hline
\end{tabular}

${ }^{a}$ Variables presented as mean (SD) or number (\%); BMI: Body mass index, SBP: Systolic blood pressure, DBP: diastolic blood pressure, AST: Aspartate aminotransferase, ALT: Alanine aminotransferase, GGT:

Gamma glutamyl transferase.

circulating levels of AST, ALT, GGT were higher in NAFLD patients compared with the controls $(P<0.001)$.

The distribution of genotypes and alleles of GHRL rs26802 and GHSR rs572169 SNPs in the NAFLD patients and controls are provided in Table 3. The carriers of the GHRL rs26802 "GG" genotype compared with the carriers of the "TT" genotype and "TT+TG" genotype were associated with decreased risks for NAFLD, and the difference remained significant even after adjustment for confounding factors including age, BMI, sex, smoking status, SBP, and DBP (P = 0.006; $\mathrm{OR}=0.14,95 \% \mathrm{CI}=0.03-0.56$ and $\mathrm{P}=0.003 ; \mathrm{OR}=0.16,95 \% \mathrm{CI}=0.05-0.53$, respectively). Nevertheless, no significant difference in genotype or allele frequencies between 
Table 3. Distribution of ghrelin (GHRL) and ghrelin receptor (GHSR) gene variants in the nonalcoholic fatty liver disease (NAFLD) patients and in the controls ${ }^{\mathrm{a}}$

\begin{tabular}{lcccc}
\hline Gene (SNP) & Controls $(n=155)$ & Patients $(n=150)$ & OR (95\% CI) & $P$-value \\
\hline GHRL (rs26802) & & & & \\
Genotype-wise comparison & $41(26.5)$ & $40(26.7)$ & 1.0 (reference) & \\
TT & $60(38.7)$ & $87(58.0)$ & $0.78(0.24-2.57)$ & 0.687 \\
TG & $54(34.8)$ & $23(15.3)$ & $0.14(0.03-0.56)$ & 0.006 \\
GG & $114(73.5)$ & $110(73.3)$ & $0.40(0.13-1.21)$ & 0.104 \\
TG and GG & $54(34.8)$ & $23(15.3)$ & $0.16(0.05-0.53)$ & 0.003 \\
GG versus others & & & \\
Allele-wise comparison & $142(45.8)$ & $167(55.7)$ & $1.0($ reference) & \\
T & $168(54.2)$ & $133(44.3)$ & $0.69(0.45-1.04)$ & 0.073 \\
G & & & & \\
GHSR (rs572169) & $87(56.1)$ & $80(53.3)$ & $1.0($ reference) & \\
Genotype-wise comparison & $56(36.1)$ & $57(38.0)$ & $1.23(0.45-3.40)$ & 0.686 \\
CC & $12(7.8)$ & $13(8.7)$ & $1.12(0.19-6.62)$ & 0.898 \\
CT & $68(43.9)$ & $70(46.7)$ & $1.21(0.47-3.13)$ & 0.693 \\
TT & $12(7.8)$ & $13(8.7)$ & $1.04(0.18-5.90)$ & 0.963 \\
CT and TT & & & \\
TT versus others & $230(74.2)$ & $217(72.3)$ & $1.0($ reference) & \\
Allele-wise comparison & $80(25.8)$ & $83(27.7)$ & $1.13(0.69-1.82)$ & 0.627 \\
C & &
\end{tabular}

${ }^{a}$ Variables presented as number (\%).

b Adjusted for age, body mass index, sex, smoking status, systolic blood pressure, and diastolic blood pressure in genotype-wise comparisons.

the two groups of patients and controls was found for GHSR SNP rs572169 either before or after adjustment for confounding factors.

\section{DISCUSSION}

This case-control study was designed to investigate whether GHRL and GHSR SNPs were associated with NAFLD risk. No significant association between the GHSR rs572169 SNP and NAFLD was found. However, our findings indicated for the first time that the GHRL rs 26802 "GG" genotype compared with the "TT" and "TT+TG" genotypes appeared to be a protective factor for NAFLD susceptibility.

The investigation of the genetic aspect of diseases provides the opportunity to explore the relationships between complex phenotypes and genomic variation [19]. These complex multifactorial diseases such as NAFLD result from the interaction between various environmental and genetic factors. Hence it is not easy to discover the majority of genes involved in their pathogenesis due to the fairly small individual effects and complex interactions of these genes. Nonetheless, one of the reliable approaches to identifying novel susceptible genes in such diseases is candidate gene association study. There is increasing evidence that ghrelin may be 
involved in the development and progression of NAFLD due to its diverse physiological functions and its role in obesity, IR, and inflammation. Patients with NAFLD have lower circulating ghrelin levels [16] and a possible hypothesis to explain this observation is obesityrelated hyperinsulinemia and the inhibitory effect of insulin on ghrelin secretion from the X/Alike cells of the stomach [20]. In accordance with this hypothesis, Saad et al. have shown that insulin can be an independent modulator of ghrelin levels, and insulin, directly or indirectly, mediates the effects of nutritional status and chronic energy balance on ghrelin levels [21].

Ghrelin, a 28-amino acid peptide, is encoded by the GHRL gene located on the short arm of chromosome 3. GHRL is a polymorphic gene and more than 200 SNPs have been found in it. Given its various biological functions, any defects in the GHRL gene may lead to obesity, IR, and inflammation which are involved in the etiology of NAFLD. As stated, a significant association between the rs26802 SNP and NAFLD susceptibility was found in the present study. The GHRL rs26802 "GG" genotype compared with the "TT" and "TT+TG" genotypes had a protective effect decreasing NAFLD susceptibility. The rs 26802 or $-501 \mathrm{~T}>\mathrm{G}$ SNP is located in intron 1 at the $5^{\prime} \mathrm{UTR}$ of the GHRL gene, and alterations in intronic sequences may influence RNA splicing and protein expression. The exact molecular mechanism through which the GHRL SNP rs26802 might participate in the etiology of NAFLD has not yet been elucidated. Nevertheless, a possible hypothesis is that the rs 26802 "T" allele of the GHRL gene gives rise to a defect in the GHRL gene, which in turn decreases ghrelin levels in the patients with NAFLD, and in this way plays a role in the pathogenesis of NAFLD through obesity, insulin resistance, or/and inflammation. Such a mechanism is still speculative but biologically plausible, and previous studies are in agreement with this hypothesis. The circulating level of ghrelin is inversely associated with BMI $[13,14]$, and it is increased after weight loss [22]. Ghrelin also stimulates GH release, which in turn leads to inhibition of fatty acids synthesis and decreased adiposity through the known lipolytic activity of GH [23]. Furthermore, ghrelin which is expressed in pancreatic islet betacells [24], plays a major role in the modulation of the insulin signaling pathway and the inhibition of glucose-stimulated insulin secretion [25, 26]. Previous studies have also reported significant negative correlations between ghrelin levels and insulin levels [14, 15], hyperinsulinemia [14], IR [13, 15], and T2D [15]. IR expedites the release of free fatty acids from adipose tissue and its influx into liver [3,27]. IR also is an independent predictor of advanced liver fibrosis [28]. The other mechanism linking ghrelin with the pathogenesis of NAFLD is inflammation. Ghrelin has anti-inflammatory and antioxidant activities [29] and it suppresses the expression of inflammatory cytokines [30]. The administration of ghrelin improves NAFLDinduced hepatic injury, oxidative stress as well as inflammation [31]. There is also more evidence that supports the hypothesis that the "G" allele of the GHRL SNP rs26802 has a protective effect against NAFLD. The rs26802 "GG" genotype presents higher circulating ghrelin levels than the "TT" genotype [32]. The "GG" carriers also have a lower BMI than the "TG" and "TT" genotypes [32]. Moreover, significant associations have been found between other GHRL SNPs and fat mass [33], visceral fat [33], serum levels of triglycerides [34], total cholesterol [35], HDL cholesterol [35], LDL cholesterol [35], glucose [36], insulin [34, 35], ghrelin [34, 37], IR [34], T2D [38], metabolic syndrome [39], hypertension [40], and hepatocellular carcinoma [41]. Finally, the circulating ghrelin level decreases in patients with either advanced liver fibrosis or liver cirrhosis and GHRL SNPs influence the progression of liver fibrosis and liver cirrhosis [42, 43]. The other possible theory linking the SNP rs26802 with NAFLD is through linkage 
disequilibrium. In other words, rs26802 may not be functional by itself, but be in linkage disequilibrium with an unknown GHRL SNP that is functional.

In the present study, no significant association between the GHSR SNP rs572169 and NAFLD susceptibility was found. The rs572169 is a synonymous amino acid substitution at position 159 in exon 1 of the coding region of the GHSR gene (Arg159Arg). Previous studies have shown that GHSR SNPs rs572169 and rs2922126 are associated with circulating glucose levels [44], obesity [45], and metabolic syndrome [44]. In spite of the biological plausibility, it appears that GHSR is not a predisposing gene for NAFLD. As mentioned earlier, in complex diseases like NAFLD, the effect of a majority of the genes may be difficult to identify owing to their modest individual effects and complex interactions. Consequently, to conclude that the GHSR gene does not have a role in the development and progression of NAFLD, the rs572169 and other GHSR SNPs should be examined in other populations.

In this study, liver biopsy was selected as the gold standard method to confirm NAFLD diagnosis. Nevertheless, some potential limitations should be acknowledged in the interpretation of our findings. First, the modest sample size of our study precluded us from doing sub-analyses. Second, by genotyping only one SNP in each gene, the coverage of the genes for this genetic association study was incomplete. Third, information on serum ghrelin levels was lacking. Despite these limitations, however, this study provided interesting data that are in line with previous publications, hence the possibility of true findings should not be excluded.

\section{CONCLUSIONS}

Our findings suggested for the first time that the GHRL rs26802 "GG" genotype compared with the "TT" and "TT+TG" genotypes appeared to be a protective factor decreasing NAFLD susceptibility. This observation is relevant from a scientific standpoint; nonetheless, further studies are needed to validate our findings.

Conflict of interest: The authors declare that they have no conflict of interest.

\section{ACKNOWLEDGMENTS}

This study was funded by Iran National Science Foundation (INSF) [grant number 90005942] and Gastroenterology and Liver Diseases Research Center, Shahid Beheshti University of Medical Sciences [grant number 1426].

\section{REFERENCES}

1. Araujo AR, Rosso N, Bedogni G, Tiribelli C, Bellentani S. Global epidemiology of non-alcoholic fatty liver disease/non-alcoholic steatohepatitis: what we need in the future. Liver Int 2018; 38(Suppl 1): 47-51.

2. Dietrich P, Hellerbrand C. Non-alcoholic fatty liver disease, obesity and the metabolic syndrome. Best Pract Res Clin Gastroenterol 2014; 28(4): 637-53. 
3. Brunt EM, Kleiner DE, Wilson LA, Unalp A, Behling CE, Lavine JE, et al. Portal chronic inflammation in nonalcoholic fatty liver disease (NAFLD): a histologic marker of advanced NAFLD-Clinicopathologic correlations from the nonalcoholic steatohepatitis clinical research network. Hepatology 2009; 49(3): 809-20.

4. Bellentani S. The epidemiology of non-alcoholic fatty liver disease. Liver Int 2017; 37(Suppl 1): 81-4.

5. Li M, Zhang S, Wu Y, Ye J, Cao X, Liu J, et al. Prevalence of insulin resistance in subjects with nonalcoholic fatty liver disease and its predictors in a Chinese population. Dig Dis Sci 2015; 60(7): 2170-6.

6. Gholam PM, Flancbaum L, Machan JT, Charney DA, Kotler DP. Nonalcoholic fatty liver disease in severely obese subjects. Am J Gastroenterol 2007; 102(2): 399-408.

7. Siddiqui MS, Fuchs M, Idowu MO, Luketic VA, Boyett S, Sargeant C, et al. Severity of nonalcoholic fatty liver disease and progression to cirrhosis are associated with atherogenic lipoprotein profile. Clin Gastroenterol Hepatol 2015; 13(5): 1000-8 e3.

8. Dabiri R, Mahmoudi T, Sabzikarian M, Asadi A, Farahani H, Nobakht H, et al. A $3^{\prime}$-untranslated region variant (rs2289046) of insulin receptor substrate 2 gene is associated with susceptibility to nonalcoholic fatty liver disease. Acta Gastroenterol Belg 2020; 83(2): 271-6.

9. Nobakht H, Mahmoudi T, Sabzikarian M, Tabaeian SP, Rezamand G, Asadi A, et al. Insulin and insulin receptor gene polymorphisms and susceptibility to nonalcoholic fatty liver disease. Arq Gastroenterol 2020; 57(2): 203-8.

10. Sabzikarian M, Mahmoudi T, Tabaeian SP, Rezamand G, Asadi A, Farahani H, et al. The common variant of rs6214 in insulin like growth factor 1 (IGF1) gene: a potential protective factor for non-alcoholic fatty liver disease. Arch Physiol Biochem 2020: 1-6.

11. Delporte C. Structure and physiological actions of ghrelin. Scientifica 2013; 2013: 518909.

12. Kojima M, Kangawa K. Ghrelin: structure and function. Physiol Rev 2005; 85(2): 495-522.

13. Ikezaki A, Hosoda H, Ito K, Iwama S, Miura N, Matsuoka H, et al. Fasting plasma ghrelin levels are negatively correlated with insulin resistance and PAI-1, but not with leptin, in obese children and adolescents. Diabetes 2002; 51(12): 3408-11.

14. Katsuki A, Urakawa H, Gabazza EC, Murashima S, Nakatani K, Togashi K, et al. Circulating levels of active ghrelin is associated with abdominal adiposity, hyperinsulinemia and insulin resistance in patients with type 2 diabetes mellitus. Eur J Endocrinol 2004; 151(5): 573-7.

15. Pöykkö SM, Kellokoski E, Hörkkö S, Kauma H, Kesäniemi YA, Ukkola O. Low plasma ghrelin is associated with insulin resistance, hypertension, and the prevalence of type 2 diabetes. Diabetes 2003; 52: 2546-53.

16. Gutierrez-Grobe Y, Villalobos-Blasquez I, Sanchez-Lara K, Villa AR, Ponciano-Rodriguez G, Ramos MH, et al. High ghrelin and obestatin levels and low risk of developing fatty liver. Ann Hepatol 2010; 9(1): 52-7.

17. Brunt EM, Janney CG, Di Bisceglie AM, Neuschwander-Tetri BA, Bacon BR. Nonalcoholic steatohepatitis: a proposal for grading and staging the histological lesions. Am J Gastroenterol 1999; 94(9): 2467-74.

18. Mahmoudi T, Karimi K, Arkani M, Farahani H, Vahedi M, Dabiri R, et al. Resistin $-420 \mathrm{C}>\mathrm{G}$ promoter variant and colorectal cancer risk. Int J Biol Markers 2014; 29(3): e233-8.

19. Atri Barzanjeh S, Behshid M, Hosseini MB, Ezari M, Taghizadeh M, Dastgiri S. Community genetic services in Iran. Genet Res Int 2012; 2012: 129575.

20. Erdmann J, Lippl F, Wagenpfeil S, Schusdziarra V. Differential association of basal and postprandial plasma ghrelin with leptin, insulin, and type 2 diabetes. Diabetes 2005; 54(5): 1371-8.

21. Saad MF, Bernaba B, Hwu CM, Jinagouda S, Fahmi S, Kogosov E, et al. Insulin regulates plasma ghrelin concentration. J Clin Endocrinol Metab 2002; 87(8): 3997-4000.

22. Hansen TK, Dall R, Hosoda H, Kojima M, Kangawa K, Christiansen JS, et al. Weight loss increases circulating levels of ghrelin in human obesity. Clin Endocrinol (Oxf) 2002; 56(2): 203-6. 
23. Jorgensen JO, Vahl N, Hansen TB, Fisker S, Hagen C, Christiansen JS. Influence of growth hormone and androgens on body composition in adults. Horm Res 1996; 45(1-2): 94-8.

24. Volante M, Allia E, Gugliotta P, Funaro A, Broglio F, Deghenghi R, et al. Expression of ghrelin and of the GH secretagogue receptor by pancreatic islet cells and related endocrine tumors. J Clin Endocrinol Metab 2002; 87(3): 1300-8.

25. Broglio F, Arvat E, Benso A, Gottero C, Muccioli G, Papotti M, et al. Ghrelin, a natural GH secretagogue produced by the stomach, induces hyperglycemia and reduces insulin secretion in humans. J Clin Endocrinol Metab 2001; 86(10): 5083-6.

26. Colombo M, Gregersen S, Xiao J, Hermansen K. Effects of ghrelin and other neuropeptides (CART, MCH, orexin A and B, and GLP-1) on the release of insulin from isolated rat islets. Pancreas 2003; 27(2): 161-6.

27. Salamone F, Bugianesi E. Nonalcoholic fatty liver disease: the hepatic trigger of the metabolic syndrome. J Hepatol 2010; 53(6): 1146-7.

28. Fujii H, Imajo K, Yoneda M, Nakahara T, Hyogo H, Takahashi H, et al. HOMA-IR: an independent predictor of advanced liver fibrosis in nondiabetic non-alcoholic fatty liver disease. J Gastroenterol Hepatol 2019; 34(8): 1390-5.

29. Takata A, Takiguchi S, Miyazaki Y, Miyata H, Takahashi T, Kurokawa Y, et al. Randomized phase II study of the anti-inflammatory effect of ghrelin during the postoperative period of esophagectomy. Ann Surg 2015; 262(2): 230-6.

30. Gonzalez-Rey E, Chorny A, Delgado M. Therapeutic action of ghrelin in a mouse model of colitis. Gastroenterology 2006; 130(6): 1707-20.

31. Li Y, Hai J, Li L, Chen X, Peng H, Cao M, et al. Administration of ghrelin improves inflammation, oxidative stress, and apoptosis during and after non-alcoholic fatty liver disease development. Endocrine 2013; 43(2): 376-86.

32. Vartiainen J, Kesaniemi YA, Ukkola O. Sequencing analysis of ghrelin gene $5^{\prime}$ flanking region: relations between the sequence variants, fasting plasma total ghrelin concentrations, and body mass index. Metabolism 2006; 55(10): 1420-5.

33. Ukkola O, Ravussin E, Jacobson P, Perusse L, Rankinen T, Tschop M, et al. Role of ghrelin polymorphisms in obesity based on three different studies. Obes Res 2002; 10(8): 782-91.

34. Zavarella S, Petrone A, Zampetti S, Gueorguiev M, Spoletini M, Mein CA, et al. A new variation in the promoter region, the $-604 \mathrm{C}>\mathrm{T}$, and the Leu72Met polymorphism of the ghrelin gene are associated with protection to insulin resistance. Int J Obes (Lond) 2008; 32(4): 663-8.

35. Takezawa J, Yamada K, Morita A, Aiba N, Watanabe S. Preproghrelin gene polymorphisms in obese Japanese: association with diabetes mellitus in men and with metabolic syndrome parameters in women. Obes Res Clin Pract 2009; 3(4): 179-91.

36. Mora M, Adam V, Palomera E, Blesa S, Diaz G, Buquet X, et al. Ghrelin gene variants influence on metabolic syndrome components in aged Spanish population. PLoS One 2015; 10(9): e0136931.

37. Hedayatizadeh-Omran A, Rafiei A, Khajavi R, Alizadeh-Navaei R, Mokhberi V, Moradzadeh K. Association between ghrelin gene (Leu72Met) polymorphism and ghrelin serum level with coronary artery diseases. DNA Cell Biol 2014; 33(2): 95-101.

38. Liao N, Xie ZK, Huang J, Xie ZF. Association between the ghrelin Leu72Met polymorphism and type 2 diabetes risk: a meta-analysis. Gene 2013; 517(2): 179-83.

39. Steinle NI, Pollin TI, O'Connell JR, Mitchell BD, Shuldiner AR. Variants in the ghrelin gene are associated with metabolic syndrome in the Old Order Amish. J Clin Endocrinol Metab 2005; 90(12): 6672-7.

40. Mager U, Kolehmainen M, Lindstrom J, Eriksson JG, Valle TT, Hamalainen H, et al. Association between ghrelin gene variations and blood pressure in subjects with impaired glucose tolerance. Am J Hypertens 2006; 19(9): 920-6. 
41. Motawi TK, Shaker OG, Ismail MF, Sayed NH. Genetic variants associated with the progression of hepatocellular carcinoma in hepatitis C Egyptian patients. Gene 2013; 527(2): 516-20.

42. Moreno M, Chaves JF, Sancho-Bru P, Ramalho F, Ramalho LN, Mansego ML, et al. Ghrelin attenuates hepatocellular injury and liver fibrogenesis in rodents and influences fibrosis progression in humans. Hepatology 2010; 51(3): 974-85.

43. Zhang X, Zhai L, Rong C, Qin X, Li S. Association of ghrelin gene polymorphisms and serum ghrelin levels with the risk of hepatitis B virus-related liver diseases in a Chinese population. PLoS One 2015; 10(11): e0143069.

44. Li WJ, Zhen YS, Sun K, Xue H, Song XD, Wang YB, et al. Ghrelin receptor gene polymorphisms are associated with female metabolic syndrome in Chinese population. Chin Med J (Engl) 2008; 121(17): 1666-9.

45. Gueorguiev M, Lecoeur C, Meyre D, Benzinou M, Mein CA, Hinney A, et al. Association studies on ghrelin and ghrelin receptor gene polymorphisms with obesity. Obesity (Silver Spring) 2009; 17(4): 745-54. 